\title{
Effects of cytochalasin B on DNA methylation and histone modification in parthenogenetically activated porcine embryos
}

\author{
Xiaoxiao $\mathrm{Hou}^{1,2, *}$, Jun $\mathrm{Liu}^{3, *}$, Zhiren Zhang ${ }^{2}$, Yanhui Zhai ${ }^{4}$, Yutian Wang ${ }^{4}$, Zhengzhu Wang ${ }^{4}$, \\ Bo Tang ${ }^{4}$, Xueming Zhang ${ }^{4}$, Liguang Sun ${ }^{1}$ and Ziyi Li ${ }^{1}$ \\ ${ }^{1}$ State and Local Joint Engineering Laboratory for Animal Models of Human Diseases, Academy of Translational \\ Medicine, First Hospital, Jilin University, Changchun, Jilin, China, ${ }^{2}$ College of Animal Science, Jilin University, \\ Changchun, Jilin, China, ${ }^{3}$ Second Hospital, Jilin University, Changchun, Jilin, China and ${ }^{4}$ College of Veterinary \\ Medicine, Jilin University, Changchun, Jilin, China \\ Correspondence should be addressed to L Sun or Z Li; Email: sunliguang1717@vip.163.com or ziyi@jlu.edu.cn
}

*(X Hou and J Liu contributed equally to this work)

\begin{abstract}
DNA methylation and histone modification play important roles in the development of mammalian embryos. Cytochalasin B (CB) is an actin polymerization inhibitor that can significantly affect cell activity and is often used in studies concerning cytology. In recent years, CB is also commonly being used in in vitro experiments on mammalian embryos, but few studies have addressed the effect of CB on the epigenetic modification of embryonic development, and the mechanism underlying this process is also unknown. This study was conducted to investigate the effects of CB on DNA methylation and histone modification in the development of parthenogenetically activated porcine embryos. Treatment with $5 \mu \mathrm{g} / \mathrm{mL}$ CB for $4 \mathrm{~h}$ significantly increased the cleavage rate, blastocyst rate and total cell number of blastocysts. However, the percentage of apoptotic cells and the expression levels of the apoptosisrelated genes $B C L-X L, B A X$ and CASP3 were significantly decreased. Treatment with CB significantly decreased the expression levels of DNMT1, DNMT3a, DNMT3b, HAT1 and HDAC1 at the pronuclear stage and promoted the conversion of 5-methylcytosine (5mC) into 5-hydroxymethylcytosine $(5 \mathrm{hmC})$. After CB treatment, the level of $\mathrm{AcH} 3 \mathrm{~K} 9$ was upregulated and the level of $\mathrm{H} 3 \mathrm{~K} 9 \mathrm{me} 3 \mathrm{was}$ downregulated. When combined with Scriptaid and 5-Aza-Cdr, CB further improved the embryonic development competence and decreased the expression of $B C L-X L, B A X$ and $C A S P 3$. In conclusion, these results suggest that CB could improve embryonic development and the quality of the blastocyst by improving the epigenetic modification during the development of parthenogenetically activated embryos.

Reproduction (2016) 152 519-527
\end{abstract}

\section{Introduction}

Precise epigenetic regulation is essential for the successful development of early embryos. The epigenetic landscape over the genome is expressed as a combination of changes in DNA methylation, histone modifications and chromatin structure; epigenetic modification results in the selective switching on or off of genes in the developing embryo (Hajkova 2010). DNA methylation is involved in chromatin compression (Choy et al. 2010) and heterochromatin formation, and usually favours transcriptional silencing (Brenet et al. 2011). Histone acetylation plays an important role in neutralizing the positive charge of the histone and in facilitating the binding of a variety of transcription factors with DNA (Dion et al. 2005). Histone methylation occurs on lysine and arginine residues. Each lysine residue can accept mono-, di- or trimethylation (me1, me2, me3), while arginine can accept mono- or dimethylation (Peterson \& Laniel 2004). Histone methylation not only induces transcriptional activation but also inhibits transcription, depending on the specific lysine residues methylated and the types of methylation (Wang et al. 2003).

Parthenogenetic activation (PA) in mammals is the activation of a MII oocyte by artificial activation such as by chemical or physical methods and the subsequent continuation of embryonic development. Parthenogenetic embryos lack the paternally expressed genes and can serve as important biological research models (Brevini \& Gandolfi 2008). Cells derived from PA embryos are not only donor cells for nuclear transfer but also act as an important source of embryonic stem cells. Human parthenogenetic embryonic stem cells (hpESCs) are gradually becoming a research hotspot because they permit a variety of ethical issues to be circumvented (Bos-Mikich et al. 2016). 
Cytochalasin B (CB) is an actin polymerization inhibitor that is commonly used in cytology studies because it can lead to multicore cells and can significantly affect cell viability (Ridler \& Smith 1968). CB is known to suppress cytokinesis without interfering with karyokinesis, and block meiosis and cleavage in oocytes and embryos (Tarkowski et al. 1977), thus inhibiting the extrusion of the second polar body and promoting the formation of diploid parthenogenetic mammalian oocytes (Fukui et al. 1992, Cha et al. 1997). In addition, CB also can be used as a cytoskeletal stabilizer (Dobrinsky 1997). In recent years, $\mathrm{CB}$ is being widely used in experimental embryology - for example, $\mathrm{CB}$ is commonly used to induce diploid or tetraploid embryos (Tarkowski et al. 1977, Somfai et al. 2006); can significantly increase the survival rate of frozen embryos (Dobrinsky et al. 2000, Dobrinsky 2001); is often used together with other modes of activation to improve embryonic development in mammalian PA (Liu et al. 2015); can alleviate the damage caused by the micromanipulation of the embryo and can ensure the chromosome ploidy of the reconstructed embryo in the process of nuclear transfer. However, the effects of $\mathrm{CB}$ on the epigenetic modification of porcine parthenogenetically activated embryos have not been reported.

Our research investigated the effects of $C B$ on the reprogramming of porcine PA embryos and on the in vitro development of porcine PA embryos. This study also addressed the effects of the methyltransferase inhibitor 5-Aza-Cdr and the novel histone deacetylase inhibitor Scriptaid together with CB on porcine PA embryos.

\section{Materials and methods}

All chemicals and reagents were purchased from Sigma unless otherwise noted.

\section{Collection and in vitro maturation of porcine oocytes}

Porcine ovaries were collected from a local abattoir and transported to the laboratory in $0.9 \% \mathrm{NaCl}$ supplemented with $200 \mathrm{IU} / \mathrm{mL}$ penicillin and streptomycin at $35-38.5^{\circ} \mathrm{C}$ within 2-4h. The cumulus-oocyte complexes (COCs) were aspirated from 3 - to $6 \mathrm{~mm}$ ovarian follicles using an 18-gage needle attached to a $10 \mathrm{~mL}$ syringe. COCs with at least three layers of cumulus cells were selected and cultured in in vitro maturation (IVM) media (Liu et al. 2012) after being washed three times in manipulation fluid (TCM-199 supplemented with $0.1 \%$ polyvinyl alcohol). Approximately 30 COCs were each cultured in a $100 \mu \mathrm{L}$ drop of maturation medium (TCM199 supplemented with $10 \mathrm{ng} / \mathrm{mL}$ epidermal growth factor, $0.5 \mu \mathrm{g} / \mathrm{mL}$ porcine luteinizing hormone, $0.5 \mu \mathrm{g} / \mathrm{mL}$ porcine follicle-stimulating hormone, $26 \mathrm{mM}$ sodium bicarbonate, $3.05 \mathrm{mM}$ glucose, $0.91 \mathrm{mM}$ sodium pyruvate, $0.57 \mathrm{mM}$ cysteine, $0.1 \%$ PVA, $10 \%$ foetal calf serum, $75 \mathrm{mg} / \mathrm{mL}$ penicillin $\mathrm{G}$ and $50 \mathrm{mg} / \mathrm{mL}$ streptomycin) for $42-44 \mathrm{~h}$ at $38.5^{\circ} \mathrm{C}$ and in a humidified atmosphere with $5 \% \mathrm{CO}_{2}$.

\section{PA of porcine oocytes and CB treatment}

The COCs were treated in manipulation fluid supplemented with $0.2 \%$ hyaluronidase to remove the cumulus cells through repeated pipetting. Oocytes with a first polar body and intact cytoplasm were considered matured and were selected for activation using two DC pulses of $1.2 \mathrm{kV} / \mathrm{cm}$ for $30 \mu$ s in fusion medium $\left(0.3 \mathrm{M}\right.$ mannitol, $1.0 \mathrm{mM} \mathrm{CaCl} \cdot 2 \mathrm{H}_{2} \mathrm{O}$, $1.0 \mathrm{mM} \mathrm{MgCl} \cdot 6 \mathrm{H}_{2} \mathrm{O}$ and $0.5 \mathrm{mM}$ HEPES). After activation of stimulation, the oocytes were divided into two groups: the control group and the experimental group. The control group was cultured in PZM-3 medium at $38.5^{\circ} \mathrm{C}$ in a humidified $5 \% \mathrm{CO}_{2}$ incubator. The experimental group was cultured in PZM-3 medium supplemented with CB (at concentrations of $2.5 \mu \mathrm{g} / \mathrm{mL}, 5 \mu \mathrm{g} / \mathrm{mL}, 7.5 \mu \mathrm{g} / \mathrm{mL}$ or $10 \mu \mathrm{g} / \mathrm{mL}$ ) for $4 \mathrm{~h}$, washed three times and then cultured in PZM-3 medium. The cleavage and blastocyst rates were calculated at 48-h and 168-h culture, respectively.

Then, the effects of the combined treatment of $C B$ with Scriptaid and/or 5-Aza-Cdr on embryonic development were examined. The parthenogenetic embryos were randomly divided into eight groups after electrical activation and were then subjected to various combinations of treatments: (1) control, blank control group without any treatment; (2) $\mathrm{CB}$, treated with $5 \mu \mathrm{g} / \mathrm{mL}$ CB for $4 \mathrm{~h}$; (3) Scriptaid, treated with $500 \mathrm{nM}$ Scriptaid for $16 \mathrm{~h}$; (4) CB+Scriptaid, treated with $500 \mathrm{nM}$ Scriptaid for $16 \mathrm{~h}$ after the $4-\mathrm{h}$ CB treatment; (5) 5-Aza-Cdr, treated with $30 \mathrm{nM}$ 5-Aza-Cdr for $48 \mathrm{~h}$; (6) $\mathrm{CB}+5-\mathrm{Aza}-\mathrm{Cdr}$, treated with $30 \mathrm{nM} 5-\mathrm{Aza}-\mathrm{Cdr}$ for $48 \mathrm{~h}$ after the 4-h CB treatment; (7) Scriptaid +5-Aza-Cdr, treated with $500 \mathrm{nM}$ Scriptaid and 30nM 5-Aza-Cdr for 16h; (8) $\mathrm{CB}+$ Scriptaid + 5-Aza-Cdr, treated with $500 \mathrm{nM}$ Scriptaid and $30 \mathrm{nM} 5$-Aza-Cdr for $16 \mathrm{~h}$ after the 4-h CB treatment.

\section{RNA isolation, RT-PCR and $q R T-P C R$}

The RNeasy Mini kit (Qiagen, Hilden, Germany) was used to extract total RNA from porcine oocytes and parthenogenetic embryos. cDNA was synthesized using the First-Strand cDNA Synthesis kit (Promega, Madison, WI, USA) according to the manufacturer's recommendations. The primers used are listed in Table 1.

SYBR Premix Ex Taq reagents (RR420A, TaKaRa, Shiga, Tokyo, Japan) were used for the quantitative real-time PCR (qRT-PCR) as per the manufacturer's instructions. The qRTPCR mix includes $10 \mu \mathrm{L}$ SYBR green premix, $0.5 \mu \mathrm{L}$ each of the forward and reverse primers $(0.5 \mu \mathrm{M}), 2 \mu \mathrm{L}$ CDNA and $7 \mu \mathrm{L} \mathrm{dH_{2 }}$ O. The qRT-PCR conditions were as follows: $30 \mathrm{~s}$ of denaturation at $95^{\circ} \mathrm{C}, 40$ cycles of PCR for quantitative analysis $\left(95^{\circ} \mathrm{C}, 5 \mathrm{~s} ; 60^{\circ} \mathrm{C}, 30 \mathrm{~s}\right)$, one cycle for melting curve analysis $\left(95^{\circ} \mathrm{C}\right.$ for $5 \mathrm{~s}, 60^{\circ} \mathrm{C}$ for $1 \mathrm{~min}, 95^{\circ} \mathrm{C}$ for $1 \mathrm{~s}$ ) and cooling at $4^{\circ} \mathrm{C}$. Relative expression for each gene was analysed using the $2^{-\triangle \triangle C T}$ method. GAPDH was used as the reference gene.

\section{Cell counting of the blastocysts}

On day 7 of culture, blastocysts were collected and fixed in $4 \%$ paraformaldehyde PBS-PVA (containing $0.1 \%$ PVA) for $30 \mathrm{~min}$ at room temperature. The numbers of cells in control 
Table 1 Primers used for qRT-PCR.

\begin{tabular}{|c|c|c|c|}
\hline Gene & Primer sequences $\left(5^{\prime}-3^{\prime}\right)$ & Annealing temperature $\left({ }^{\circ} \mathrm{C}\right)$ & Product size (bp) \\
\hline$B C L-X L$ & $\begin{array}{l}\text { F: CTTACCTGAATGACCACCTAGAGC } \\
\text { R: CCGACTGAAGAGCGAACCC }\end{array}$ & 60 & 182 \\
\hline$B A X$ & $\begin{array}{l}\text { F: CGGGACACGGAGGAGGTTT } \\
\text { R: CGAGTCGTATCGTCGGTTG }\end{array}$ & 60 & 189 \\
\hline CASP3 & $\begin{array}{l}\text { F: ACTGTGGGATTGAGACGG } \\
\text { R: GGAATAGTAACGAGGTGCTG }\end{array}$ & 55 & 110 \\
\hline OCT4 & $\begin{array}{l}\text { F: GTCGCCAGAAGGGCAAAC } \\
\text { R: CAGGGTGGTGAAGTGAGGG }\end{array}$ & 57 & 125 \\
\hline NANOG & $\begin{array}{l}\text { F: CCCCGAAGCATCCATTTCC } \\
\text { R: CGAGGGTCTCAGCAGATGACAT }\end{array}$ & 58 & 101 \\
\hline SOX2 & $\begin{array}{l}\text { F: CCCTGCAGTACAACTCCATGAC } \\
\text { R: GGTGCCCTGCTGCGAGTA }\end{array}$ & 59 & 86 \\
\hline DNMT1 & $\begin{array}{l}\text { F: GGCAGACCACCATCACATC } \\
\text { R: GGAGCAGTCCGGCAACT }\end{array}$ & 55 & 165 \\
\hline DNMT3a & $\begin{array}{l}\text { F: GGACAAGAATGCCACCAAATCA } \\
\text { R: CTTGCCGTCTCCGAACCA }\end{array}$ & 60 & 196 \\
\hline DNMT3b & $\begin{array}{l}\text { F: GGGTGGAAAGACACGGGAT } \\
\text { R: TAGGAGCGTAGAAGCAAGGAA }\end{array}$ & 60 & 243 \\
\hline HAT1 & $\begin{array}{l}\text { F: GACTGTGTGGAGGCAGATGATGTA } \\
\text { R: GAGAACCGAGTATGTATGGAGTAAGG }\end{array}$ & 60 & 150 \\
\hline HDAC1 & $\begin{array}{l}\text { F: GCTGGCAAAGGCAAGTATTATG } \\
\text { R: CACACTGTAAGACGACCGCAC }\end{array}$ & 60 & 139 \\
\hline H19 & $\begin{array}{l}\text { F: CTCAAACGACAAGAGATGGT } \\
\text { R: AGTGTAGTGGCTCCAGAATG }\end{array}$ & 58 & 122 \\
\hline IGF2 & $\begin{array}{l}\text { F: AAGAGTGCTCTTCCGTAG } \\
\text { R: TGTCATAGCGGAAGAACTTG }\end{array}$ & 58 & 156 \\
\hline GAPDH & $\begin{array}{l}\text { F: CAAATTCATTGTCGTACCAG } \\
\text { R: АCACTCACTCTTCTACСTTTG }\end{array}$ & 60 & 90 \\
\hline
\end{tabular}

and experimental blastocysts were counted after staining with $10 \mu \mathrm{g} / \mathrm{mL}$ Hoechst 33342 using UV with a fluorescence microscope. Images were captured and processed using Nikon NIS Elements software.

\section{Apoptosis assays on the blastocysts}

At day 7 , blastocysts were collected, and the zona pellucida was removed by treatment with $0.5 \%$ Pronase. After being fixed in $4 \%$ paraformaldehyde for $30 \mathrm{~min}$, the blastocysts were permeabilized in $0.3 \%$ Triton $\mathrm{X}-100$ for $30 \mathrm{~min}$ at room temperature, washed three times in PBS-PVA and incubated with TUNEL solution (In Situ Cell Death Detection Kit, Roche; Mannheim, Germany) in the darkness for $1 \mathrm{~h}$ at $37^{\circ} \mathrm{C}$. In the negative control group, the embryos were incubated with fluorescein-conjugated dUTP only. In the positive control group, embryos were pre-treated with DNase (Roche) for $10 \mathrm{~min}$ at $15-25^{\circ} \mathrm{C}$. After TUNEL labelling, embryos were washed three times in PBS-PVA and then incubated in Hoechst 33342 for $10 \mathrm{~min}$ to stain all nuclei. Afterward, the embryos were mounted onto glass slides beneath a cover slip and examined using a fluorescence microscope.

\section{Immunofluorescence staining}

The zona pellucida of porcine oocytes and embryos were digested by treatment with $0.5 \%$ Pronase in PZM-3 at $38.5^{\circ} \mathrm{C}$ for $5 \mathrm{~min}$. After washing for three times in PBS-PVA, zona pellucida-free oocytes and embryos were fixed with $4 \%$ paraformaldehyde for $30 \mathrm{~min}$ at room temperature, permeabilized for $30 \mathrm{~min}$ with $0.3 \%$ Triton $\mathrm{X}-100$ prepared in PBS-PVA and then blocked for $1 \mathrm{~h}$ at room temperature in PBS-PVA with 3\% BSA. Following incubation overnight at $4{ }^{\circ} \mathrm{C}$ with primary antibodies targeting $5 \mathrm{mC}$ and $5 \mathrm{hmC}$ (diluted 1:200 v/v; Eurogentec), AcH3K9 (diluted 1:200 v/v; Abcam) and H3K9me3 (diluted 1:200 v/v; Abcam), the oocytes and embryos were washed in PBS-PVA and stained with Alexa Fluor 488 goat anti-rabbit (1:200 v/v; Invitrogen), Alexa Fluor 594 goat anti-rabbit (1:200 v/v; Invitrogen) and Alexa Fluor 488 goat anti-mouse $\left(1: 200 \mathrm{v} / \mathrm{v}\right.$; Invitrogen) at $37^{\circ} \mathrm{C}$ for $2 \mathrm{~h}$. DNA was stained with $10 \mu \mathrm{g} / \mathrm{mL}$ Hoechst 33342 for $10 \mathrm{~min}$. All samples were immediately mounted and observed under a fluorescence microscope. The images of the control and experimental groups were captured using the same microscope settings and exposure time. The average fluorescence intensity of the nuclear areas was calculated using ImageJ.

Table 2 Effect of different concentration of CB on the development in parthenogenetically activated porcine embryos.

\begin{tabular}{|c|c|c|c|}
\hline Concentration of $\mathbf{C B}(\mu \mathrm{g} / \mathrm{mL})$ & No. of embryos treated & No. of embryos cleaved (\%) & No. of blastocysts (\%) \\
\hline 0 & 621 & $439(70.38 \pm 1.3)^{\mathrm{a}}$ & $114(18.39 \pm 1.3)^{\mathrm{a}}$ \\
\hline 2.5 & 340 & $261(75.23 \pm 2.2)^{\mathrm{ac}}$ & $90(23.49 \pm 1.4)^{\mathrm{a}}$ \\
\hline 5 & 431 & $379(87.48 \pm 1.2)^{\mathrm{b}}$ & $146(33.31 \pm 2.3)^{b}$ \\
\hline 7.5 & 300 & $264(88.52 \pm 2.3)^{b}$ & $102(33.24 \pm 1.4)^{\mathrm{b}}$ \\
\hline 10 & 300 & $236(79.35 \pm 2.1)^{c}$ & $76(25.00 \pm 3.2)^{\mathrm{a}}$ \\
\hline
\end{tabular}

Data are mean \pm SE of at least three trials. Values in the same column with different superscripts differ significantly $(P<0.05)$. 

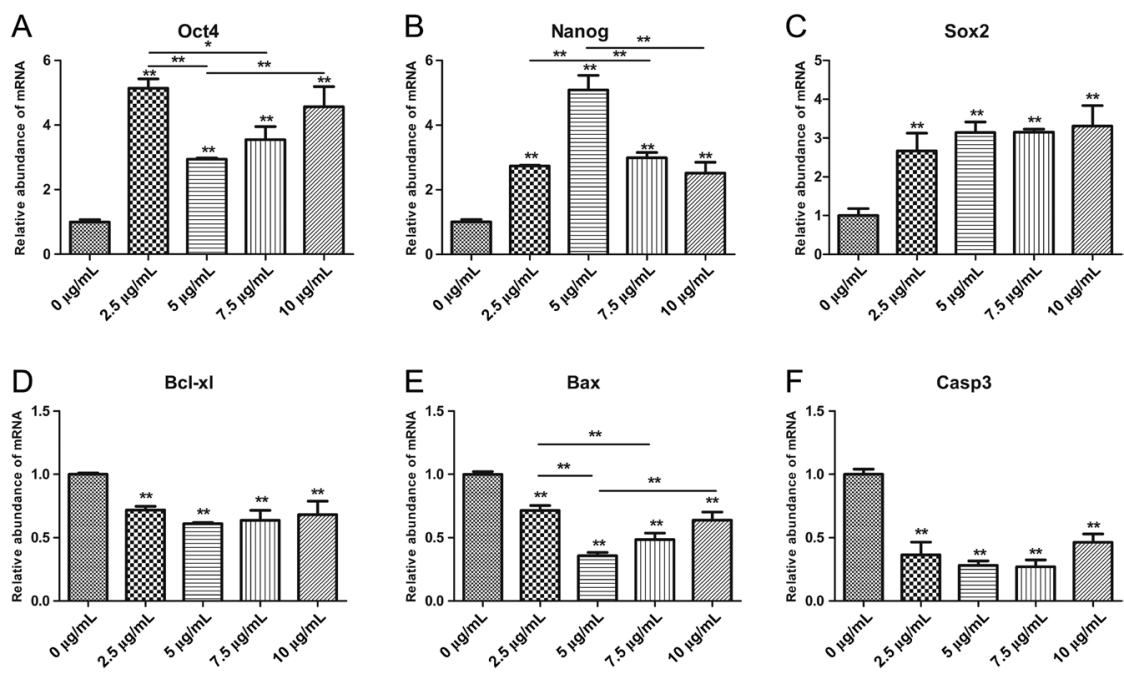

Figure 1 Relative expression levels of the pluripotency genes OCT4, NANOG and SOX2 and the apoptosis-related genes $B C L-X L, B A X$ and CASP 3 in parthenogenetically activated porcine blastocysts treated with different concentrations of $\mathrm{CB}$. GAPDH was used as an internal control. The gene expression levels in blastocysts in the control group were used for sample calibration (expression set to 1 ), and the expression levels of genes at each CB concentration were compared to those in the control group. All data were expressed as mean \pm S.D. Asterisks denote significant effects: ${ }^{*} P<0.05,{ }^{* *} P<0.01$, compared with $0 \mu \mathrm{g} / \mathrm{mL}$.

\section{Statistical analysis}

All experiments were replicated at least three times. Statistical analysis was carried out using SPSS (Statistical Package for the Social Sciences) 19.0 software (Chicago, IL, USA) by one-way ANOVA. $P<0.05$ was considered statistically significant, and $P<0.01$ was considered extremely statistically significant.

\section{Results}

\section{Effects of different concentrations of $C B$ on the development of parthenogenetically activated porcine embryos}

The experimental groups were treated with $2.5 \mu \mathrm{g} / \mathrm{mL}$, $5 \mu \mathrm{g} / \mathrm{mL}, 7.5 \mu \mathrm{g} / \mathrm{mL}$ or $10 \mu \mathrm{g} / \mathrm{mL} \mathrm{CB}$, and the control group was treated with $0 \mu \mathrm{g} / \mathrm{mL}$ CB. After electrical activation, the oocytes were treated with $\mathrm{CB}$ for $4 \mathrm{~h}$ and then transferred to PZM-3 for continued development. The cleavage rates ( $48 \mathrm{~h}$ after activation) of embryos treated with $5 \mu \mathrm{g} / \mathrm{mL}$ CB $(87.48 \%)$ or $7.5 \mu \mathrm{g} / \mathrm{mL}$ CB $(88.52 \%)$ were significantly higher than those
(70.38-79.35\%) of the other groups, including the control group. Consistent with this, the experimental groups treated with $5 \mu \mathrm{g} / \mathrm{mL} \mathrm{CB}(33.31 \%)$ or $7.5 \mu \mathrm{g} / \mathrm{mL}$ CB (33.24\%) had higher blastocyst rates (168 h after activation) compared with other groups (18.39-25.00\%). However, the cleavage and blastocyst rates did not significantly differ between the groups treated with $5 \mu \mathrm{g} / \mathrm{mL} \mathrm{CB}$ and $7.5 \mu \mathrm{g} / \mathrm{mL}$ CB (Table 2).

The qRT-PCR results showed that the expression levels of the pluripotent genes OCT4, NANOG and SOX2 (Fig. 1A, B and C) were significantly increased, while the expression of apoptosis-related genes $B C L-X L, B A X$ and CASP3 (Fig. 1D, E and F) was significantly decreased in all experimental groups. In particular, the group treated with $5 \mu \mathrm{g} / \mathrm{mL}$ CB showed a significantly higher expression of NANOG (Fig. 1B) and significantly lower expression of $B A X$ (Fig. 1E) than the other groups. Based on these results, $5 \mu \mathrm{g} / \mathrm{mL}$ was chosen as the optimal concentration of $\mathrm{CB}$ and used in the following experiments.
A

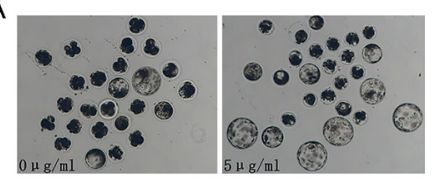

$\mathrm{B}$

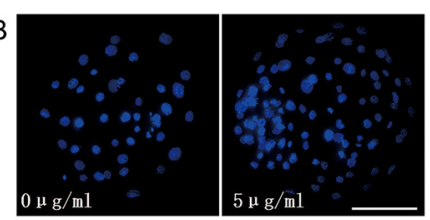

C

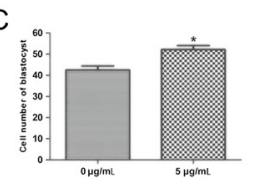

E

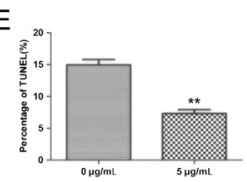

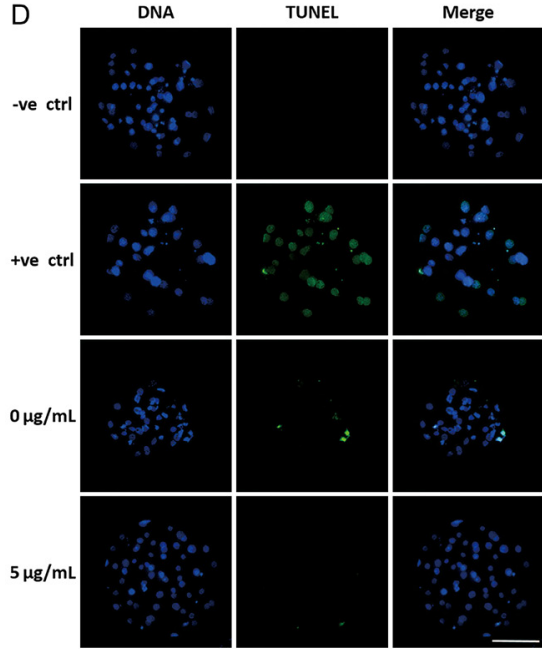

Figure 2 Assessment of total cell number and apoptosis in the control group and the group treated with $5 \mu \mathrm{g} / \mathrm{mL}$ CB at the blastocyst stage. The fragmented nuclei (green) are apoptotic; each sample was counterstained with Hoechst 33342 to visualize DNA (blue). Scale bar: $100 \mu \mathrm{m}$. (A) Embryos at $168 \mathrm{~h}$ activation in the control group and the group treated with $5 \mu \mathrm{g} / \mathrm{mL}$ CB. Magnification: $\times 30$. (B and C) Total cell numbers of blastocysts in the control group and the group treated with $5 \mu \mathrm{g} / \mathrm{mL} \mathrm{CB}$. The data are presented as mean \pm S.D. $* P<0.05$, compared with blastocyst in control group. (D and $\mathrm{E}$ ) Percentage of apoptotic cells in each group at the blastocyst stage. The data are presented as mean \pm S.D. ${ }^{* *} P<0.01$, compared with blastocysts in the control group. 
Effects of CB treatment on cell number and apoptosis rate of parthenogenetically activated porcine blastocysts

The total cell number of per blastocyst and the percentage of apoptotic cells in blastocysts were determined in the control group and the group treated with $5 \mu \mathrm{g} / \mathrm{mL}$ CB. The average total cell number of blastocysts treated with $5 \mu \mathrm{g} / \mathrm{mL}$ CB was significantly higher than that of control blastocysts (51.48 vs 44.13 ; Fig. $2 \mathrm{~B}$ and C). The percentage of apoptotic cells in blastocysts was significantly lower in those treated with $5 \mu \mathrm{g} / \mathrm{mL} C B$ than in control blastocysts (Fig. 2D and E).

\section{Effects of CB treatment on the DNA methylation and histone modification in parthenogenetically activated porcine embryos}

Preimplantation mammalian embryos undergo extensive epigenetic reprogramming. To investigate the changes in DNA methylation and histone modification during the development of porcine parthenogenetic embryos treated with $C B$, the mRNA levels of the methyltransferases DNMT1, DNMT3a and DNMT3b and of the histone acetyltransferase HAT1 and the histone deacetylase HDAC1 were examined at GV, MII, pronuclear, 2-cell, 4-cell, 8-cell, morula and blastocyst stages, as well as the protein levels of $5 \mathrm{mC}, 5 \mathrm{hmC}$, $\mathrm{AcH} 3 \mathrm{~K} 9$ and $\mathrm{H} 3 \mathrm{~K} 9 \mathrm{me} 3$. The $\mathrm{CB}$ treatment significantly decreased the levels of DNMT1, DNMT3a, DNMT3b, HAT1 and HDAC1 (Fig. 3A, B, C, D and E) at the pronuclear stage. However, the expression of HDAC1 was obviously upregulated at 8-cell and morula stages (Fig. 3E). Based on quantification of the fluorescence intensity, in all stages examined, the level of $\mathrm{AcH} 3 \mathrm{~K} 9$ (Fig. 3G and J) increased with $\mathrm{CB}$ treatment, while the level of $\mathrm{H} 3 \mathrm{~K} 9 \mathrm{me} 3$ (Fig. $3 \mathrm{H}$ and J) significantly decreased. Meanwhile, the expression of $5 \mathrm{hmC}$ increased (Fig. 3F and $\mathrm{I}$ ) and the expression of $5 \mathrm{mC}$ decreased (Fig. 3F
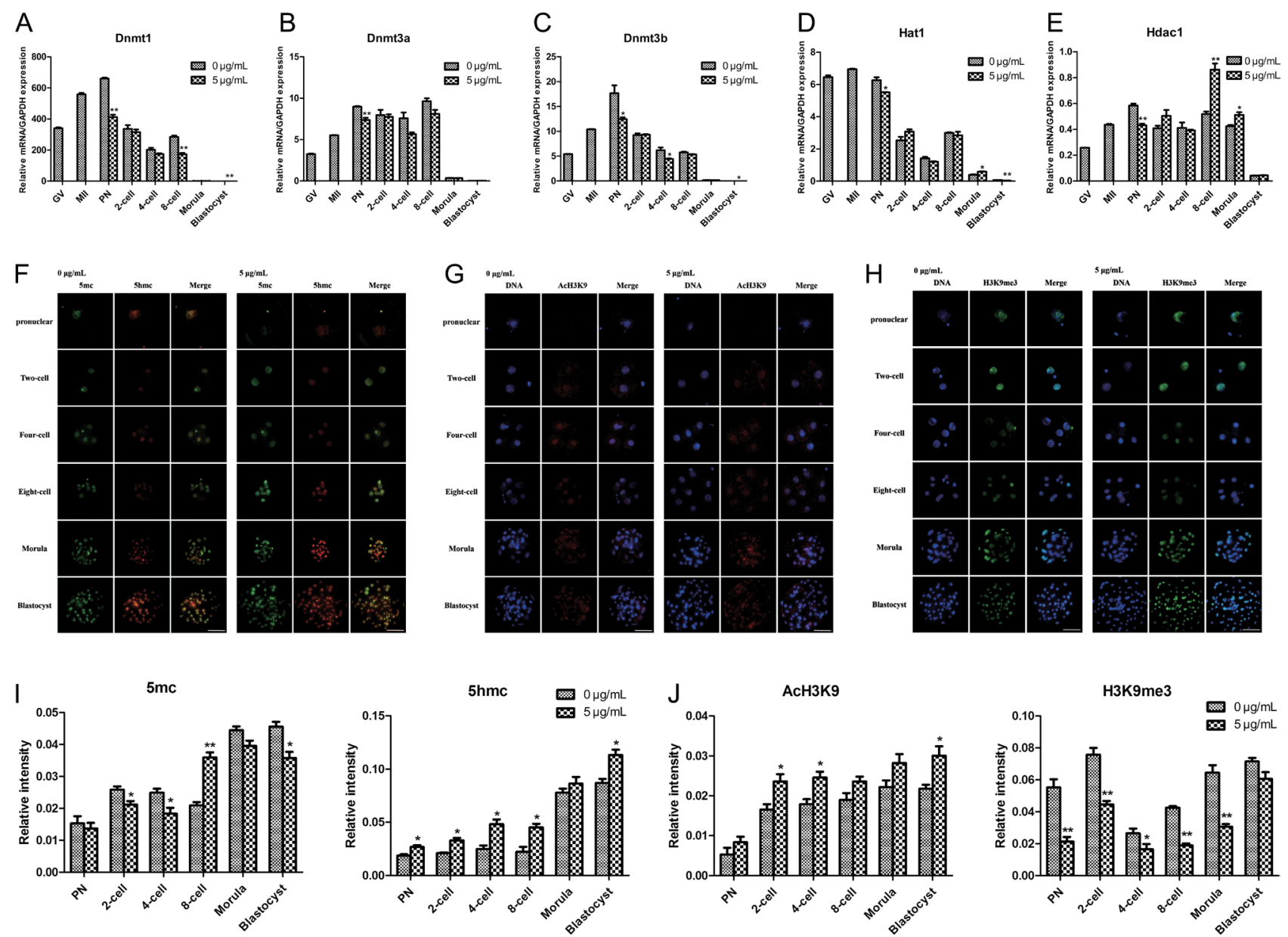

Figure 3 DNA methylation and histone modification in the control and CB $(5 \mu \mathrm{g} / \mathrm{mL})$ groups at different stages of development after parthenogenetic activation in porcine embryos. GAPDH was used as an internal control. (A-E) The relative abundances of DNMT1, DNMT3a, DNMT3b, HAT1 and HDAC1 mRNA at the GV to blastocyst stages in the CB group and the control group. (F-H) Immunofluorescence staining for $5 \mathrm{mC}$ (green) $/ 5 \mathrm{hmC}$ (red), $\mathrm{AcH} 3 \mathrm{~K} 9$ (red) and $\mathrm{H} 3 \mathrm{~K} 9 \mathrm{me} 3$ (green) in preimplantation parthenogenetic porcine embryos. DNA (blue) was stained with Hoechst 33342. Scale bars: $100 \mu \mathrm{m}$. (I and J) Fluorescence intensity analysis of $5 \mathrm{mC} / 5 \mathrm{hmC}$, AcH3K9 and H3K9me3 in preimplantation parthenogenetic porcine embryos. The relative intensity levels in the control group at the pronuclear stage were used for sample calibration (expression set to 1). The data are all expressed as mean \pm S.D. $* P<0.05, * * P<0.01$, compared with $0 \mu \mathrm{g} / \mathrm{mL}$. 

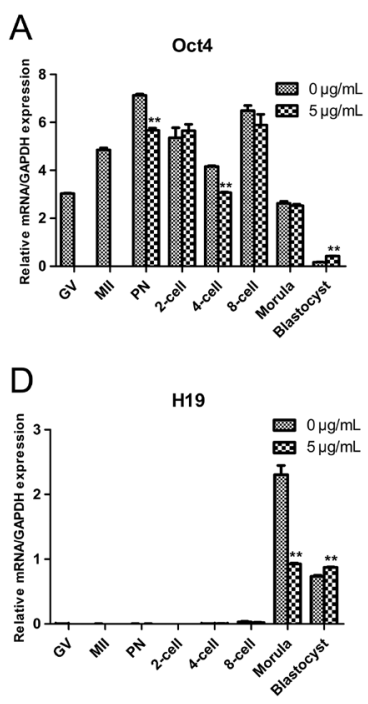
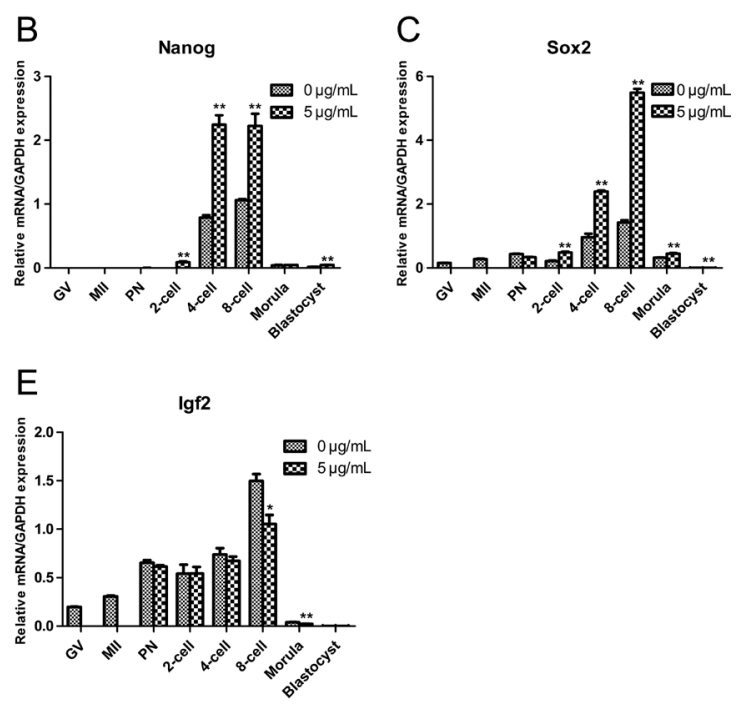

Figure 4 The relative mRNA abundances of the pluripotency genes OCT4, NANOG and SOX2 and the imprinted genes H19 and IGF2 at the GV to blastocyst stages in the CB and control groups. GAPDH was used as an internal control. The data are all expressed as mean \pm S.D., and the expression level of each gene at each stage was compared between the CB group and the control group. ${ }^{*} P<0.05$, $* * P<0.01$, compared with $0 \mu \mathrm{g} / \mathrm{mL}$. and I) in most stages except the 8-cell stage, when the $5 \mathrm{mC}$ level unexpectedly increased and remained stable during later development.

\section{Effects of CB treatment on pluripotency-related genes and imprinted genes in parthenogenetically activated porcine embryos}

qRT-PCR was used to examine the expression levels of the pluripotency genes OCT4, NANOG and SOX2 and the imprinted genes $\mathrm{H} 19$ and IGF2 at all stages of preimplantation embryos, including the GV, MII, pronuclear, 2-cell, 4-cell, 8-cell, morula and blastocyst stages. The mRNA expression levels of OCT4, NANOG and SOX2 (Fig. 4A, B and C) were significantly higher in CB-treated embryos than in control embryos at the blastocyst stage. The expression of NANOG (Fig. 4B) was especially high in the 4-cell and 8-cell stages, and SOX2 expression showed a similar pattern (Fig. 4C).

The paternally imprinted gene H19 (Fig. 4D) showed very low expression before the morula stage and high expression after the morula stage. Conversely, the maternally imprinted gene IGF2 (Fig. 4E) was mainly expressed before the morula stage, with almost no expression after that stage. The CB treatment significantly decreased the levels of H19 and IGF2 at some stages but did not change their expression trends.

\section{Effects of CB combined with Scriptaid and/or 5-Aza- Cdr on the development of parthenogenetically activated porcine embryos}

Treatment with Scriptaid alone significantly increased the cleavage and blastocyst rates of parthenogenetic embryos, and it was not significantly different from the CB treatment group. Besides, the cleavage rate further increased in embryos treated with $\mathrm{CB}+$ Scriptaid. Treatment with 5-Aza-Cdr alone significantly increased the cleavage and blastocyst rates of parthenogenetic embryos, and the blastocyst rate of $\mathrm{CB}+5-\mathrm{Aza}-\mathrm{Cdr}$ combined treatment group increased further and becomes equal to that in the embryos in the group treated with CB alone. Scriptaid+5-Aza-Cdr combined treatment increased the cleavage rate rather than the blastocyst rate of PA embryos, whereas CB + Scriptaid + 5-Aza-Cdr combined treatment significantly increased both the cleavage and the blastocyst rates (Table 3).

The expression of the apoptosis-related genes $B C L-X L, B A X$ and CASP3 in each group was detected by fluorescence quantitative PCR. The levels of

Table 3 Effect of CB, Scriptaid and 5-Aza-Cdr on the development in parthenogenetically activated porcine embryos.

\begin{tabular}{lccc}
\hline Group & No. of embryos treated & No. of embryos cleaved (\%) & No. of blastocysts $(\%)$ \\
\hline Control & 724 & $548(75.69 \pm 2.3)^{\mathrm{a}}$ & $123(17.42 \pm 1.2)^{\mathrm{a}}$ \\
CB & 421 & $358(85.04 \pm 1.3)^{\mathrm{b}}$ & $130(30.88 \pm 2.2)^{\mathrm{b}}$ \\
Scriptaid & 359 & $290(80.81 \pm 3.3)^{\mathrm{b}}$ & $98(27.27 \pm 2.3)^{\mathrm{b}}$ \\
CB+S & 354 & $327(92.35 \pm 2.1)^{\mathrm{c}}$ & $102(28.82 \pm 1.1)^{\mathrm{b}}$ \\
5-Aza-Cdr & 424 & $366(86.13 \pm 0.9)^{\mathrm{b}}$ & $104(24.89 \pm 1.3)^{\mathrm{c}}$ \\
CB+A & 179 & $156(85.38 \pm 2.5)^{\mathrm{b}}$ & $102(30.57 \pm 1.7)^{\mathrm{b}}$ \\
S+A & 258 & $258(86.57 \pm 3.1)^{\mathrm{b}}$ & $52(18.42 \pm 3.3)^{\mathrm{a}}$ \\
CB+S+A & 169 & $155(91.33 \pm 2.1)^{\mathrm{c}}$ & $50(30.05 \pm 3.2)^{\mathrm{b}}$ \\
\hline
\end{tabular}

Data are mean \pm SE of at least three trials. Values in the same column with different superscripts differ significantly $(P<0.05)$. A, 5-Aza-Cdr; S, Scriptaid. 

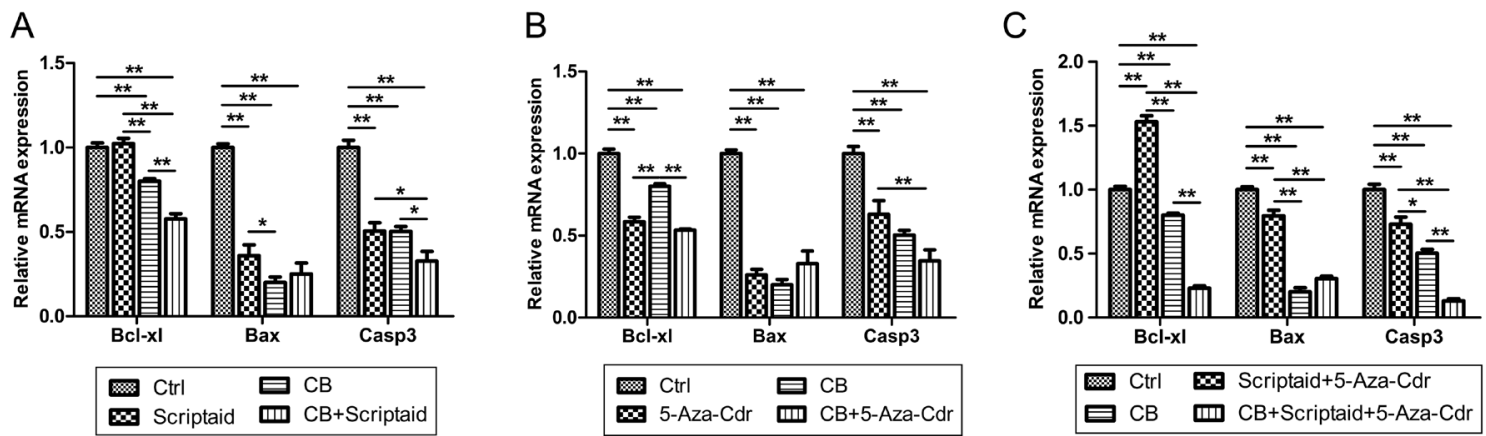

Figure 5 Relative expression levels of the apoptosis-related genes $B C L-X L, B A X$ and $C A S P 3$ in porcine parthenogenetic blastocysts in different treatment groups. GAPDH was used as an internal control. The gene expression levels in the control group of blastocysts were used for sample calibration (expression set to 1), and the expression levels of genes at each group were compared to the levels of expression at the blastocyst stage in the control group. The data are all expressed as mean \pm S.D. Asterisks denote significant effects: ${ }^{*} P<0.05,{ }^{* *} P<0.01$, compared with $0 \mu \mathrm{g} / \mathrm{mL}$.

the pro-apoptotic genes $B A X$ and CASP3 were significantly downregulated with Scriptaid treatment, while $\mathrm{CB}+$ Scriptaid combined treatment blocked the expression of the anti-apoptotic gene $B C L-X L$ and the pro-apoptotic gene CASP3 (Fig. 5A). The 5-Aza$\mathrm{Cdr}$ treatment downregulated the levels of $B C L-X L$, $B A X$ and CASP3; thus, $C B+5-A z a-C d r$ combined treatment further decreased the expression of CASP3 (Fig. 5B). Combined treatment with Scriptaid +5-Aza$\mathrm{Cdr}$ significantly increased the level of $B C L-X L$ and significantly decreased the levels of $B A X$ and $C A S P 3$, but $\mathrm{CB}+$ Scriptaid + 5-Aza-Cdr combined treatment sharply decreased the expression levels of $B C L-X L, B A X$ and CASP3 (Fig. 5C).

\section{Discussion}

During mammalian embryonic development, extensive epigenetic reprogramming occurs in both the paternal and the maternal genomes. Proper epigenetic modification is essential for the formation of healthy embryos. Epigenetic modifications, such as DNA methylation and histone modification, usually act cooperatively to regulate gene expression in mammals (Delcuve et al. 2009). DNA methylation mediates transcriptional silencing in mammalian cells, while histone acetylation facilitates the binding of transcription factors to DNA (Dion et al. 2005). Histone methylation can induce transcriptional activation or inhibit transcription, depending on the methylation of specific lysine residues (Wang et al. 2003). In mammalian parthenogenetic evaluation, CB is usually combined with other types of activation to improve embryonic development. However, the association between CB and epigenetic modification has not been reported. Here, the changes in DNA methylation and histone modification in the development of preimplantation embryos were detected after CB treatment, which will provide new insights for further study of the roles of epigenetic modification in embryonic development.
In this study, treatment with $5 \mu \mathrm{g} / \mathrm{mL}$ or $7.5 \mu \mathrm{g} / \mathrm{mL} \mathrm{CB}$ produced significantly higher embryonic cleavage and blastocyst rates than those observed in the other groups, which is similar to the results of porcine embryos (Liu et al. 2015). The expression levels of the anti-apoptotic gene $B C L-X L$ and the pro-apoptotic genes $B A X$ and CASP3 at the blastocyst stage were lower in CB-treated embryos than in control embryos. To further confirm the apparent reduction in apoptosis in the blastocysts, a TUNEL assay was conducted; the results showed that CB inhibited apoptosis in the blastocysts. This indicated that although anti-apoptotic genes were downregulated along with pro-apoptotic genes upon $\mathrm{CB}$ treatment, $\mathrm{CB}$ still increased the vitality of blastocysts. Furthermore, statistical analysis showed that CB treatment increased the cell number of the PA blastocysts. These results indicated that $5 \mu \mathrm{g} / \mathrm{mL} \quad \mathrm{CB}$ is beneficial to the development of porcine PA embryos and significantly improves the quality of the blastocysts.

Previous studies have shown that knockdown or overexpression of DNMT1 is detrimental to in vitro embryo development and can even lead to embryonic lethality (Biniszkiewicz et al. 2002, Huan et al. 2015). It has also been reported that DNMT3a ${ }^{-1-}$ mice show incomplete foetal development with death occurring within 4 weeks after birth, and no viable DNMT3 $b^{-1-}$ mice were recovered at birth (Okano et al. 1999). Acetylation levels are the result of the balance of the activities of histone acetyltransferases (HATs) and histone deacetylases (HDACs). The decreased expression of HDAC1 in mouse oocytes and embryos may have a negative impact on embryonic development (Li et al. 2011). Our results suggested that $\mathrm{CB}$ treatment significantly decreased the levels of DNMT1, DNMT3a, DNMT3b, HAT1 and HDAC1 at the pronuclear stage and promoted the conversion of $5 \mathrm{mC}$ into $5 \mathrm{hmC}$. Meanwhile, CB reduced the levels of $\mathrm{H} 3 \mathrm{~K} 9 \mathrm{me} 3$ while increasing the levels of $\mathrm{AcH} 3 \mathrm{~K} 9$ in most stages of embryonic development. $\mathrm{H} 3 \mathrm{~K} 9$ is known as an important active site for acetylation and 
methylation (Xiong et al. 2013). Methylation of H3K9 mediates gene silencing and is linked to the formation of heterochromatin (Peters et al. 2002). Our results showed that the addition of $\mathrm{CB}$ decreased the overall methylation level of the embryo at the pronuclear stage and induced hyperacetylation by reducing the histone methylation level and increasing the histone acetylation state of the embryo, which is beneficial to the transcription of genes and the activation of the embryo. These results provided evidence that CB can improve the development of embryos by altering the epigenetic modification of the embryo.

Disruption of /GF2/H19 expression in parthenogenetic foetuses and placentas has been detected in swine parthenogenesis, and an increased concentration of IGF2 enhances preimplantation development (Han et al. 2013). In this study, expression of IGF2 gradually increased from the GV stage to the 8-cell stage and then sharply declined at the morula and blastocyst stages, which impaired the development of embryos. The CB treatment did not change this trend. In contrast to the expression of IGF2, H19 showed almost no expression before the 8-cell stage, but it showed significantly increased expression at the morula and blastocyst stages, consistent with a previous study (Park et al. 2011). A similar expression pattern has also been detected in mouse (Sotomaru et al. 2002). The abnormal expression of H19 in mice is lethal (Brunkow \& Tilghman 1991), whereas downregulation of $\mathrm{H} 19$ can promote mouse parthenogenetic embryonic stem cells to completely differentiate into the three germ layers (Ragina et al. 2012). In this study, CB treatment could significantly reduce the expression of $\mathrm{H} 19$ in the morula and the expression of IGF2 in the 8-cell stage. These results confirmed that the defect in the expression of imprinted genes can be improved but not change the trend by CB-induced regulation of epigenetic modification.

Scriptaid is a novel histone deacetylation inhibitor, which has been reported to be beneficial for nuclear transfer (SCNT) or parthenogenetic embryos in vitro (Zhao et al. 2010, Liang et al. 2015). It is reported that Scriptaid significantly enhanced the development of SCNT embryos to the blastocyst stage, but decreased the percentage of blastocysts of PA embryos (Zhao et al. 2009). It is not consistent with our results. The difference may be caused by differences in activation and embryo manipulation. 5-Aza-Cdr is an effective inhibitor of methyltransferases; a low concentration of 5-Aza-Cdr can promote the development of mammalian embryos (Ding et al. 2008). According to our research, treatment with Scriptaid and/or 5-Aza-Cdr improved the parthenogenetic embryo cleavage rate or the blastocyst rate. When it was combined with CB treatment, the cleavage rate or blastocyst rate increased further. The role of CB is different from those of Scriptaid and 5-AzaCdr; CB does not have any effect on methyltransferase or histone deacetylase but instead adjusts the overall epigenetic state of the embryo to improve embryonic development. Based on our experimental results, we hypothesized that $\mathrm{CB}$ played a compensatory role when interacting with Scriptaid and/or 5-Aza-Cdr, such that the overall epigenetic modification of the embryo was more beneficial to embryonic development. The combined effect of Scriptaid and 5-Aza-Cdr on the improvement of embryonic development was not better than that treated with Scriptaid or 5-Aza-Cdr individually. This finding conflicts with the findings of previous studies showing that the combination of HDAC and DNMT inhibitors can significantly enhance the developmental capacity of mammalian embryos in vitro (Ding et al. 2008, $\mathrm{Xu}$ et al. 2013). This discrepancy might be caused by the different types of inhibitors, different concentrations and different effect periods, which made the HDAC and DNMT inhibitors induce excessive inhibition, thereby counteracting the effects of either inhibitor alone. Moreover, $\mathrm{CB}$ treatment downregulated the expression of $B C L-X L, B A X$ or CASP3 compared with the Scriptaid, $5-A z a-C d r$ and Scriptaid +5-Aza-Cdr treatments. These results suggested that $\mathrm{CB}$ treatment improves the developmental capacity of parthenogenetically activated porcine embryos and has a direct relationship with the expression of apoptosis-related genes.

In conclusion, this study demonstrates that $\mathrm{CB}$ treatment improves the development and quality of parthenogenetically activated porcine embryos. The reduced expression of the DNMT genes promotes the conversion of $5 \mathrm{mC}$ into $5 \mathrm{hmC}$ and induces the decrease of the overall methylation level of embryos. At the same time, the level of histone acetylation increases and histone methylation decreases, activating transcription and promoting the expression of pluripotency genes. CB can further promote embryonic development when combined with Scriptaid and/or 5-Aza-Cdr. Our findings demonstrate that $C B$ enhances the epigenetic modification of embryos and induces overall demethylation and hyperacetylation, thereby upregulating the expression of genes critical for the development of porcine parthenogenetic embryos.

\section{Declaration of interest}

The authors declare that there is no conflict of interest that could be perceived as prejudicing the impartiality of the research reported.

\section{Funding}

This work was supported by grants from the National Basic Research Program (973 Program) (No. 2011CB944204) and the Ministry of Education Innovation Research Team in University (IRT1248) in China. 


\section{Acknowledgements}

The authors thank the American Journal Experts (www.aje. com) for the English language review.

\section{References}

Biniszkiewicz D, Gribnau J, Ramsahoye B, Gaudet F, Eggan K, Humpherys D, Mastrangelo MA, Jun Z, Walter J \& Jaenisch R 2002 Dnmt1 overexpression causes genomic hypermethylation, loss of imprinting, and embryonic lethality. Molecular and Cellular Biology 22 2124-2135. (doi:10.1128/MCB.22.7.2124-2135.2002)

Bos-Mikich A, Bressan FF, Ruggeri RR, Watanabe Y \& Meirelles FV 2016 Parthenogenesis and human assisted reproduction. Stem Cells International 2016 1970843. (doi: 10.1155/2016/1970843)

Brenet F, Moh M, Funk P, Feierstein E, Viale AJ, Socci ND \& Scandura JM 2011 DNA methylation of the first exon is tightly linked to transcriptional silencing. PLOS ONE 6 e14524. (doi:10.1371/journal.pone.0014524)

Brevini IAL \& Gandolfi F 2008 Parthenotes as a source of embryonic stem cells. Cell Proliferation 41 20-30. (doi:10.1111/j.13652184.2008.00485.x)

Brunkow ME \& Tilghman SM 1991 Ectopic expression of the H19 gene in mice causes prenatal lethality. Genes Development 5 1092-1101. (doi:10.1101/gad.5.6.1092)

Cha SK, Kim NH, Lee SM, Baik CS, Lee HT \& Chung KS 1997 Effect of cytochalasin B and cycloheximide on the activation rate, chromosome constituent and in vitro development of porcine oocytes following parthenogenetic stimulation. Reproduction, Fertility and Development 9 441-446. (doi:10.1071/R96078)

Choy JS, Wei S, Lee JY, Tan S, Chu S \& Lee TH 2010 DNA methylation increases nucleosome compaction and rigidity. Journal of the American Chemical Society 132 1782-1783. (doi:10.1021/ja910264z)

Delcuve GP, Rastegar M \& Davie JR 2009 Epigenetic control. Journal of Cellular Physiology 219 243-250. (doi:10.1002/jcp.21678)

Ding X, Wang Y, Zhang D, Wang Y, Guo Z \& Zhang Y 2008 Increased pre-implantation development of cloned bovine embryos treated with 5-aza-2'-deoxycytidine and trichostatin A. Theriogenology 70 622-630. (doi:10.1016/j.theriogenology.2008.04.042)

Dion MF, Altschuler SJ, Wu LF \& Rando OJ 2005 Genomic characterization reveals a simple histone $\mathrm{H} 4$ acetylation code. PNAS 102 5501-5506. (doi:10.1073/pnas.0500136102)

Dobrinsky JR 1997 Cryopreservation of pig embryos. Journal of Reproduction and Fertility Supplement 52 301-312.

Dobrinsky JR 2001 Cryopreservation of swine embryos: a chilly past with a vitrifying future. Theriogenology 56 1333-1344. (doi:10.1016/S0093691X(01)00634-3)

Dobrinsky JR, Pursel VG, Long CR \& Johnson LA 2000 Birth of piglets after transfer of embryos cryopreserved by cytoskeletal stabilization and vitrification. Biological Reproduction 62 564-570. (doi:10.1095/ biolreprod62.3.564)

Fukui Y, Sawai K, Furudate M, Sato N, Iwazumi Y \& Ohsaki K 1992 Parthenogenetic development of bovine oocytes treated with ethanol and cytochalasin B after in vitro maturation. Molecular Reproduction and Development 33 357-362. (doi:10.1002/ mrd.1080330318)

Hajkova P 2010 Epigenetic reprogramming - taking a lesson from the embryo. Current Opinion in Cell Biology 22 342-350. (doi:10.1016/ j.ceb.2010.04.011)

Han XL, Ouyang HS, Chen XJ, Huang YY, Song YN, Zhang MJ, Pang DX, Lai LX \& Li ZJ 2013 Aberrant expression of Igf2/H19 in porcine parthenogenetic fetuses and placentas. Animal Reproduction Science 139 101-108. (doi:10.1016/j.anireprosci.2013.04.008)

Huan Y, Xie B, Liu S, Kong Q \& Liu Z 2015 A novel role for DNA methyltransferase 1 in regulating oocyte cytoplasmic maturation in pigs. PLOS ONE 10 e0127512. (doi:10.1371/journal.pone.0127512)

Li JJ, Pei Y, Zhou GB, Suo L, Wang YP, Wu GQ, Fu XW, Hou YP \& Zhu SE 2011 Histone deacetyltransferase 1 expression in mouse oocyte and their in vitro-fertilized embryo: effect of oocyte vitrification. Cryoletters 32 13-20.

Liang S, Zhao MH, Choi JW, Kim NH \& Cui XS 2015 Scriptaid treatment decreases DNA methyltransferase 1 expression by induction of
microRNA-152 expression in porcine somatic cell nuclear transfer embryos. PLoS ONE 10 e0134567. (doi:10.1371/journal.pone.0134567)

Liu LM, Song GQ, Cao F, Guan JY, Tang B \& Li ZY 2012 Transient exposure to sodium butyrate after germinal vesicle breakdown improves meiosis but not developmental competence in pig oocytes (vol 36, pg 483, 2012). Cell Biology International 36 689-689. (doi:10.1002/j.1095-8355.2012. tb02228.x)

Liu S, Cui K, Li HL, Sun JM, Lu XR, Shen KY, Liu QY \& Shi de S 2015 Comparison of chemical, electrical, and combined activation methods for in vitro matured porcine oocytes. In Vitro Cellular and Developmental Biology - Animal 51 103-112. (doi: 10.1007/s11626-014-9819-1)

Okano M, Bell DW, Haber DA \& Li E 1999 DNA methyltransferases Dnmt3a and Dnmt3b are essential for de novo methylation and mammalian development. Cell 99 247-257. (doi:10.1016/S0092-8674(00)81656-6)

Park CH, Uh KJ, Mulligan BP, Jeung EB, Hyun SH, Shin T, Ka H \& Lee CK 2011 Analysis of imprinted gene expression in normal fertilized and uniparental preimplantation porcine embryos. PLOS ONE 6 e22216. (doi:10.1371/journal.pone.0022216)

Peters AHFM, Mermoud JE, O'Carroll D, Pagani M, Schweizer D, Brockdorff N \& Jenuwein T 2002 Histone H3 lysine 9 methylation is an epigenetic imprint of facultative heterochromatin. Nature Genetics $\mathbf{3 0}$ 77-80. (doi:10.1038/ng789)

Peterson CL \& Laniel MA 2004 Histones and histone modifications. Current Biology 14 R546-R551. (doi:10.1016/j.cub.2004.07.007)

Ragina NP, Schlosser K, Knott JG, Senagore PK, Swiatek PJ, Chang EA, Fakhouri WD, Schutte BC, Kiupel M \& Cibelli JB 2012 Downregulation of $\mathrm{H} 19$ improves the differentiation potential of mouse parthenogenetic embryonic stem cells. Stem Cells and Development 21 1134-1144. (doi:10.1089/scd.2011.0152)

Ridler MA \& Smith GF 1968 The response of human cultured lymphocytes to cytochalasin B. Journal of Cell Science 3 595-602.

Somfai T, Ozawa M, Noguchi J, Kaneko H, Ohnuma K, Karja NW, Fahrudin M, Maedomari N, Dinnyes A, Nagai T et al. 2006 Diploid porcine parthenotes produced by inhibition of first polar body extrusion during in vitro maturation of follicular oocytes. Reproduction 132 559-570. (doi:10.1530/rep.1.01216)

Sotomaru Y, Katsuzawa Y, Hatada I, Obata Y, Sasaki H \& Kono T 2002 Unregulated expression of the imprinted genes $\mathrm{H} 19$ and Igf2 $r$ in mouse uniparental fetuses. Journal of Biological Chemistry 277 12474-12478. (doi:10.1074/jbc.M109212200)

Tarkowski AK, Witkowska A \& Opas J 1977 Development of cytochalasin in B-induced tetraploid and diploid/tetraploid mosaic mouse embryos. Journal of Embryology and Experimental Morphology 41 47-64.

Wang HB, An WJ, Cao R, Xia L, Erdjument-Bromage H, Chatton B, Tempst P, Roeder RG \& Zhang Y 2003 mAM facilitates conversion by ESET of dimethyl to trimethyl lysine 9 of histone $\mathrm{H} 3$ to cause transcriptional repression. Molecular Cell 12 475-487. (doi:10.1016/ j.molcel.2003.08.007)

Xiong XR, Lan DL, Li J, Zhong JC, Zi XD, Ma L \& Wang Y 2013 Zebularine and scriptaid significantly improve epigenetic reprogramming of yak fibroblasts and cloning efficiency. Cellular Reprogramming 15 293-300.

Xu WH, Li ZC, Yu B, He XY, Shi JS, Zhou R, Liu DW \& Wu ZF 2013 Effects of DNMT1 and HDAC inhibitors on gene-specific methylation reprogramming during porcine somatic cell nuclear transfer. PLoS ONE 8 e64705. (doi:10.1371/journal.pone.0064705)

Zhao J, Ross JW, Hao Y, Spate LD, Walters EM, Samuel MS, Rieke A, Murphy CN \& Prather RS 2009 Significant improvement in cloning efficiency of an inbred miniature pig by histone deacetylase inhibitor treatment after somatic cell nuclear transfer. Biological Reproduction $\mathbf{8 1}$ 525-530. (doi:10.1095/biolreprod.109.077016)

Zhao JG, Hao YH, Ross JW, Spate LD, Walters EM, Samuel MS, Rieke A, Murphy CN \& Prather RS 2010 Histone deacetylase inhibitors improve in vitro and in vivo developmental competence of somatic cell nuclear transfer porcine embryos. Cellular Reprogramming 12 75-83. (doi:10.1089/cell.2009.0038)

Received 19 May 2016

First decision 4 July 2016

Revised manuscript received 12 August 2016

Accepted 31 August 2016 